\title{
Vivendo entre jovens: a observação participante como metodologia de pesquisa de campo ${ }^{1}$
}

\section{Living among young people: participant observationas a methodology of field research}

\author{
Nécio Turra Neto \\ necioturra@fct.unesp.br \\ Universidade Estadual Paulista
}

\begin{abstract}
Resumo:Aolongoda minha trajetóriaacadêmica, tenhoconfrontado,como problemática de pesquisa, a territorialização das culturas juvenis transterritoriais punk e hip-hop. A observação participante revelou-se como uma metodologia frutífera, na produção de informações sobre o cotidiano de jovens que tecem redes de sociabilidade e territoriais em torno delas, em contextos urbanos específicos. O objetivo aqui é apresentar esta trajetória de pesquisa, as principais referências teóricas que fundamentaram a opção metodológica, bem como algumas orientações práticas, baseadas na minha própria experiência com observação participante. Entremeando estas orientações, as culturas juvenis são desveladas. Por fim, problematizo a especificidade da Geografia no estudo da territorialização das juventudes. Com isso, espero ter atendido aos objetivos da mesa redonda "Microterritorialidades urbanas: perspectivas teórico-metodológicas".
\end{abstract}

Palavras-chave: Observação Participante. Juventudes. Território. Pesquisa.

Abstract: Throughout my academic life, I have faced problems regarding research on the territorialization of transterritorial punk and hip-hop youth cultures. The participant observation proved to be a fruitful methodology towards the production of information, about the daily life of these young people, which builds these same people's networks of sociability and territorials in specific urban contexts. This article aims at presenting its research path, the main theoretical references which motivated our methodological option, as well as some practical orientations based on my own experience with participant observation. Weaving these orientations, youth cultures are unveiled. Finally, I present the specificity of Geography in the study of territorialization of youths.

Keywords: Participant observation. Youths. Territory. Research.

Resumen: A lo largo de mi trayectoria académica he sido confrontado con el problema de la pesquisa de la territorialización de las culturas juveniles transterritoriales punk y hip-hop. La observación participante se demostró como una metodología fructífera para la producción de informaciones acerca del cotidiano de los jóvenes que tejen redes de sociabilidad y territoriales alrededor de ellos en los contextos urbanos específicos. El objetivo de este trabajo es presentar la trayectoria de investigación, las principales referencias teóricas que fundamentan la opción metodológica, así como

1 O texto que se segue é resultado de uma fala realizada na mesa redonda "Microterritorialidades urbanas: perspectivas teórico-metodológicas", como parte do I Seminário sobre Microterritorialidades Urbanas, ocorrido em novembro de 2010, na Universidade Luterana do Brasil, Campus de Canoas/RS. 
algunas orientaciones prácticas basadas en mi propia experiencia con la observación participante. Intercalando estas orientaciones, las culturas juveniles se desvelan. Por último, se analiza la especificidad de la Geografía en el estudio de la territorialización de los jóvenes

Palabras clave: Observación participante. Juventud. Territorio. Investigación.

\section{INTRODUÇÃO}

Interagir com jovens, a fim de melhor compreendê-los/as, constitui, certamente, um grande desafio para a pesquisa acadêmica, ainda mais na atualidade, em que a velocidade das mudanças faz com que alguns anos de diferença pareçam um abismo geracional intransponível em termos de referências culturais.

Neste texto, pretendo desenvolver uma discussão sobre a metodologia da observação participante, que é uma possibilidade de transpor abismos culturais, como o foi (e ainda é) importante meio pelo qual antropólogos/as têm realizado esta transposição, ao longo da história da sua disciplina, de onde vêm, aliás, as principais referências apresentadas aqui.

A discussão metodológica não tem sido, propriamente, uma preocupação central na Geografia Brasileira, mas o tema tem ganhado destaque nos últimos anos, quando se passou a perceber que, no quadro das Ciência Humanas e, mais particularmente, no campo das pesquisas qualitativas com sujeitos sociais, mais do que coletar dados - que estariam ali na realidade, como que disponíveis, só esperando o pesquisador ou pesquisadora deles se apropriar -, na verdade, as informações (das quais derivam as conclusões) são produzidas no próprio processo de pesquisa. Nesse sentido, a forma como os trabalhos de campo são conduzidos, as interações ali estabelecidas, a leitura que fazem os sujeitos sobre o pesquisador/a em campo interferem imensamente na natureza e na qualidade das informações que aparecem. Desse modo, as metodologias empregadas, longe de serem neutras, dizem muito sobre as possibilidades e limites das conclusões a que a pesquisa pode conduzir, visto que sua matéria-prima é resultado de contingentes processos de interação social.

Nenhum processo de pesquisa que assume (num trabalho de reflexão sobre si mesmo) esta condição pode se pretender portador da "última palavra" sobre a realidade estudada, mas reconhece sua condição de interpretação limitada e parcial, aquela que foi possível elaborar, a partir das informações que a metodologia de pesquisa permitiu virem à tona.

É nesse sentido que a preocupação metodológica tem se imposto à Geografia Brasileira, como forma de produzir pesquisas mais autorreflexivas e que minimamente saibam avaliar tanto as potencialidades e limitações das suas metodologias e instrumentos de produção de informação, quanto relativizar criticamente suas conclusões, no estudo de grupos sociais. 
No caso em foco, a observação participante pode ser definida como uma interação face a face, com o grupo estudado, com objetivo de produzir informações. Essa metodologia originou-se no campo da Antropologia, em sua incursão por tribos indígenas, nas quais o/a pesquisador/a realizava um processo de imersão, em que o estranhamento e o choque iniciais, com uma cultura completamente diferente, aos poucos se transmutavam em familiaridade. Era por esse processo, de transformar o "exótico" em familiar, que se produzia conhecimento sobre as outras culturas ${ }^{2}$.

A despeito das vinculações positivistas de tal metodologia, quando a Antropologia voltou seus olhos para a cultura urbana, a observação participante continuou sendo bastante empregada, mas agora com maior grau de autorreflexão, problematizando o encontro e, muitas vezes, o confronto, entre um pesquisador/a com suas teorias e a densidade da realidade social, no seu acontecer cotidiano.

Uma ciência pautada nessa metodologia e na reflexão sobre seu próprio fazer-se só poderia se autocompreender como uma ciência modesta, que se reconhece enquanto apenas uma interpretação possível da realidade, passível de crítica; uma ciência que reconhece a intervenção da subjetividade do pesquisador/a, na produção e na análise da informação, afinal trata-se de uma ciência dialógica, no sentido de que as informações sobre as quais se pauta são produzidas na interação entre sujeitos - pesquisador/a e informantes.

Trata-se de uma ciência dialógica também num outro sentido, pois, como não tem a pretensão de dar a última palavra sobre os fatos, cria um espaço de diálogo com os/ as leitores/as que, de posse da descrição detalhada do processo investigativo e das evidências que conduziram à conclusão (uma forma de elaboração do material empírico característica de pesquisas dessa natureza), pode também participar, tecendo sua própria interpretação.

Todavia, como a opção metodológica não é o ponto de partida para a proposição da pesquisa, e sim a consequência de outras opções, no plano teórico e no plano da problemática a ser investigada, julgo necessário apresentar alguns dos pressupostos que me conduziram a optar pela observação participante, antes de entrar propriamente na sua operacionalização.

\section{PRESSUPOSTOS DA OPÇÃO METODOLÓGICA}

Tenho trabalhado com observação participante ao longo da minha trajetória acadêmica na pós-graduação e, depois, na formação de jovens pesquisadores. Esta opção não deriva apenas de uma identidade entre pesquisador e metodologia, mas do fato de que a observação participante tem respondido, com certo grau de eficiência e confiabilidade, as demandas de um fazer científico, que tem se colocado como tema de pesquisa o estudo

2 Estranhamento, para alguns autores de metodologia de trabalho de campo, é condição fundamental para a descrição etnográfica. $\mathrm{O}$ olhar o outro a partir do que ele tem de diferente e curioso, essa é a postura que se deve ter no campo. Da Matta (1978, p. 28), por exemplo, afirma que: “... só se tem Antropologia Social quando se tem de algum modo o exótico [...] estranhamento." 
das vivências cotidianas de grupos juvenis na cidade, em torno dos estilos culturais punk e hip-hop. Nesse sentido, é importante dizer que não existem metodologias perfeitas - e nem estou defendendo que a observação participante o seja -, mas tão somente metodologias que são mais (ou menos) adequadas, para a produção das informações necessárias à resposta de problemas de pesquisa, orientados teoricamente.

É por isso que julgo importante apresentar, ainda que de forma resumida, para os limites deste artigo, alguns dos pressupostos que me levaram a empregar esta metodologia na condução das pesquisas com os grupos juvenis. Trata-se das concepções de cultura e de juventude, bem como da problemática central em torno da qual se desenvolvem as pesquisas.

De acordo com Claval (1997), ao colocar os sujeitos sociais no centro de sua análise, a Geografia Cultural (campo a partir do qual penso estar falando), foi obrigada a desenvolver novas abordagens de cultura. Inspirado na linguística e na teoria da comunicação, o autor argumenta que "a cultura é feita de informações que circulam entre os indivíduos e lhes permitem agir" (p. 94). Os conteúdos das mensagens comunicadas só podem ser compreendidos por aqueles que participam do contexto em que esses códigos são conhecidos. "

Esta perspectiva sublinha que a cultura é antes uma realidade de escala local [...] não existe compreensão real dos processos culturais se negligenciamos o jogo da intersubjetividade" (p. 95). Esta ideia é reforçada pelo mesmo autor em outro texto (CLAVAL, 1999), quando apresenta os "círculos de intersubjetividade", em que cada um vive e evolui, como o lócus gerador da cultura do indivíduo.

Nesse mesmo sentido, coloco a argumentação que Geertz (1978) desenvolve no seu texto clássico sobre o ofício etnográfico. O autor argumenta que, no seu conceito semiótico de cultura, o ser humano é visto como "um animal amarrado a teias de significado" (p. 15). A cultura seria essa teia e o trabalho de analisá-la seria feito por uma ciência interpretativa, que buscaria os significados.

Para esse autor, a cultura é pública. Cada ato ou gesto transmite uma informação para aqueles que conhecem os seus significados. A cultura, assim, não seria um poder ao qual se pode atribuir causalmente o ato e o gesto, mas é um contexto, dentro do qual eles podem ser lidos e descritos.

Para conhecê-los, é preciso familiarizar-se com o universo imaginativo, que dá sentido ao ato e ao gesto. Isso não significa que seja necessário se tornar parte do grupo em estudo, mas sim, que é fundamental conseguir conversar com seus membros, e não apenas como estranhos (GEERTZ, 1978). É aí que está a chave para pensar a observação participante como uma metodologia de pesquisa, que possibilita a concretização desse diálogo - num contexto local, onde se estabelece o jogo da intersubjetividade e onde os atos e gestos cotidianos ganham sentido.

Também numa certa concepção de juventudes, a metodologia da observação participante é bastante indicada para tornar empíricos pressupostos teóricos.

Alguns autores têm colocado o contraponto entre o que seria uma perspectiva mais unitária e uma mais diversificada da juventude. Dayrell (2005) e Pais (2003), a partir 
de diferentes denominações, acabam tratando (se entendi bem) da mesma situação: de um lado, uma visão da juventude a partir do que seria comum a todos/as os/as jovens, independente da classe social e do contexto urbano, uma perspectiva que Pais chama de geracional, que encara a juventude como fase de vida e, por outro lado, uma perspectiva que procura contextualizar as juventudes e vê-las em sua diversidade.

Para além dessa polarização, os autores argumentam que existem algumas características que podem ser atribuídas para todas as juventudes, que existem pontos em que os/as jovens de diferentes contextos se assemelham, mas que a forma como cada grupo juvenil, no seu contexto socioespacial, realiza essas características, assumidas por eles como formas especificamente juvenis de existir, varia consideravelmente, obedecendo a condicionamentos sociais, econômicos, culturais - e espaciais. Emerge daí um conceito de juventude bastante plástico, que articula, em cada contexto, o geral e o particular, o mundo e o lugar, o unitário e o diverso, a ponto de estes mesmos autores tratarem de juventudes no plural e não mais no singular.

Para Dayrell (2005), inclusive, mais do que buscar modelos de juventudes, ligados às imagens que se construíram historicamente no senso comum e mesmo na Sociologia, é preferível se perguntar pelos modos de ser jovem. Considera que a noção de juventude não deve mais estar "[...] presa a critérios rígidos, mas sim [ser entendida] como parte de um processo de crescimento mais totalizante, que ganha contornos específicos no conjunto das experiências vivenciadas pelos indivíduos em seu contexto social" (p. 33).

Portanto, podemos pensar em pesquisas sobre juventudes que estão menos preocupadas em ser um processo de construção teórica, por uma abstração ascendente, a partir de realidades empíricas diversas, do que um procedimento de imersão num contexto particular, em busca de uma especificidade de modos de realização, para o qual a observação participante também faz todo o sentido.

O terceiro pressuposto diz respeito à minha própria trajetória de pesquisa. Tenho procurado, ao longo dos anos, refletir sobre identidades juvenis que são transterritoriais (CANCLINI, 1996) e seu processo de territorialização em contextos urbanos diversos (TURRA NETO, 2004; 2008). Refiro-me aqui ao estudo das culturas juvenis punk e hip-hop, nas cidades de Londrina e de Guarapuava, no Paraná.

As conclusões das referidas pesquisas indicaram uma relação muito estreita entre o lugar e o mundo na produção localizada dos agrupamentos juvenis. Trata-se da produção de identidades culturais a partir de referências globais, que chegam aos lugares pela mídia, mas que, ao se inserirem em novos contextos espaço-temporais, territorializam-se, transformando-se e transformando o lugar, pois aí passam a coexistir com referências culturais já existentes.

Tais considerações aproximaram-me de McDowell (1996, p. 181), quando argumenta que "o atual desafio que une os geógrafos culturais é a investigação de como as interconexões entre forças globais e particularidade local alteram os relacionamentos entre identidade, significado e lugar."

Nesse sentido, um dos problemas de pesquisa que tenho perseguido é: qual a natureza das referências identitárias disponíveis no lugar (na cidade), para os jovens 
construírem seus grupos de sociabilidade e, a partir deles, desenharem sua territorialidade no espaço urbano, demarcando-o com essas referências e dialogando com os outros grupos sociais ali presentes, também a partir delas? Como essas culturas são apropriadas e vividas no lugar e quais tensões produzem?

Cidade e lugar são, assim, tanto contexto como condição para a realização de grupos de sociabilidade juvenis, articulados a partir de referências culturais transterritoriais. Esses grupos ocupam o espaço urbano, as ruas, praças, espaços de lazer e diversão, constituem na cidade uma trama territorial formada por circuitos, ou mesmo por territórios mais bem delimitados. Colocam-se no cenário urbano, espacializam-se, ao mesmo tempo em que sua presença confere aos espaços, novos significados e identidades. E é por estarem ali, por fazerem circular suas referências culturais na cidade, que esses grupos juvenis apresentam-se como possibilidades de identificação, para crianças e adolescentes que, circulando, também estão em busca de novas referências.

Para desvendar estas tramas cotidianas de territorialização, a opção metodológica da observação participante mostrou-se particularmente frutífera. Ela tem possibilitado uma aproximação em relação aos diversos agrupamentos juvenis, na qual é possível realizar uma imersão nesses universos, acompanhando, junto com os jovens e as jovens, a tessitura das suas redes de sociabilidade e das suas redes territoriais - processos que são, no fundo, indissociáveis, mas também pleno de tensões, negociações e confrontos.

\section{OBSERV AÇÃO PARTICIPANTE - ASPECTOS OPERACIONAIS}

Um dos principais desafios da metodologia em foco é a entrada no grupo a ser estudado. Trata-se de um processo de negociação, de conquista da confiança e também de tensões. Os sujeitos sociais não têm obrigação nenhuma em aceitar uma pessoa diferente do grupo e que pretende observá-los constantemente. Rejeições sutis ou mais explícitas podem levar os/as pesquisadores/as menos persistentes a desistirem, ou a procurarem outras metodologias menos interativas.

Não existe receita para transpor essa barreira inicial. O que se recomenda, na literatura, é que o pesquisador e pesquisadora evitem o uso de máscaras e que se mostrem abertos a uma interação sem formalidades, próxima, e que procurem manter sempre uma atitude de respeito e ética diante dos seus sujeitos pesquisados. Para estes, pouco importa as bases lógicas da pesquisa, mais vale a pessoa que a pesquisadora ou o pesquisador revelam ser. É nessa dimensão humana que se pauta a confiança, que o grupo pode (ou não) depositar no/a "intruso/a".

Nesse primeiro momento, há também a necessidade do grupo em situar $\mathrm{o} / \mathrm{a}$ pesquisador/a no quadro do seu universo simbólico, se casado/a, separado/a, jovem ou mais velho/a, branco, preto, amarelo, heterossexual ou homossexual. Cada elemento de identidade do/a pesquisador/a pode jogar a favor, ou criar alguns limites à interação, conforme os critérios do grupo. Nesse sentido, também, as informações que emergem numa pesquisa dessa natureza serão sempre parciais e condicionadas à interação que foi possível estabelecer. 
No caso de uma pesquisa com grupos juvenis, penso que outra preocupação também se impõe: não se trata de uma diferença apenas cultural, mas também etária, que distingue o/a pesquisador/a do grupo estudado. Ninguém consegue esconder algumas rugas e cabelos brancos por muito tempo e tentar passar-se por mais jovem do que é pode descambar para o ridículo. Nesse caso, a farsa se revela e a credibilidade perante os/as jovens se esvai. É preciso encarar os desafios, os constrangimentos mútuos, as hostilidades e desconfianças (quando existem) de ser mais velho (ou muito mais velho) entre jovens. Com o passar do tempo, a familiaridade vai tomando o lugar do estranhamento, os/as jovens vão descobrindo o que o pesquisador/a está fazendo ali e vão respeitá-lo/a, se a recíproca for verdadeira. Mas, ter esperanças de que os/as jovens interajam com o pesquisador/a, tal como fazem entre si, pode levar a algumas frustrações.

Em todo caso, as impressões iniciais tendem a se desvanecer quando a convivência passa a acontecer. Um conhecimento mais profundo entre os sujeitos envolvidos na pesquisa (o da investigação e o investigado) tende a se estabelecer, num processo de desvendamento mútuo, ao cabo do qual, o/a pesquisador/a passa, então, a fazer parte do universo sob observação - ao mesmo tempo modificando e sendo modificado por este contexto, como diria Cicourel (1980).

Durante o campo, muitas das atividades observadas só são conhecidas no momento da observação. Não foram previstas nas teorias - que fundamentaram a elaboração do plano de trabalho, por exemplo -, de modo que tendem a causar certo espanto e sensação de vertigem. O trabalho de campo é sempre imponderável. Não há como prever o que pode acontecer, nem o que se vai dialogar com os sujeitos da pesquisa.

Dessa forma, o campo é uma aventura, na qual as questões formuladas pelo projeto de pesquisa podem, rapidamente, perder importância, diante de novas questões que não haviam sido sequer formuladas. É preciso manter uma escuta atenta para não deixar escapar aquilo que pode colocar em xeque as teorias, no afã de querer confirmá-las no campo.

Quando iniciei a pesquisa na cena punk de Londrina, por exemplo, estabelecendo meu primeiro contato efetivo com essa cultura, tinha em mente alguns estereótipos, construídos no diálogo com livros e imagens difundidas como modelo do ser punk, além de certo investimento utópico na pesquisa. Pensava em encontrar um grupo juvenil intensamente politizado e engajado em ações de transformação social; territórios bem delimitados e defendidos em embates, às vezes encarniçados, tal como se estivesse diante de uma cidade sitiada. A experiência do punk foi derrubando um a um esses estereótipos fáceis e revelando, no fundo, jovens vivendo suas vidas como punks e encarando os vários dilemas colocados para quem assume essa identidade - na relação com outros grupos juvenis, nas relações familiares e com a escola.

Também o território mostrou-se mais complexo - do que a imagem da cidade sitiada e dividida em diversas "tribos urbanas". Deparei-me com um território punk bastante móvel, acompanhando a trajetória histórica da cena local e da própria cidade; territórios diversos, nem sempre exclusivos, mas, às vezes, com certa tensão no ar, quando grupos diferentes projetavam-se sobre os mesmos espaços. 
Percebi que, ao longo do tempo, várias já haviam sido as referências espaciais da cena punk londrinense: bares que logo fecharam, prédios abandonados que foram demolidos, pontos no centro em que se reuniam muitos punks, quando a cena era bastante forte. E entre os territórios conhecidos, no momento da pesquisa, coexistiam aqueles mais públicos, formados por ruas, praças e calçadão, e aqueles mais privados, formados por bares e mesmo pela casa de algum dos punks. Uma trama territorial complexa, feita de trajetórias, cruzamentos, rotinas e também dinâmica, resultado de um processo ininterrupto de "des-re-territorialização" (HAESBAERT, 2004), próprio da trajetória localizada desta cultura juvenil.

Certamente, não teria conseguido chegar a essas conclusões se não tivesse exercitado a escuta atenta, o acompanhamento cotidiano, experimentando junto com os jovens o que eles experimentavam, no momento em que o faziam. Certamente, também, não teria chegado a estas conclusões e a vivência entre jovens não teria valido de nada se não tivesse registrado todas as informações no diário de campo, mesmo as que, num primeiro momento, não considerava relevante.

Se não é possível planejar o campo, se na experiência junto com os grupos juvenis (e não só com eles), é preciso deixar-se conduzir pela fluidez dos acontecimentos, é também imprescindível que uma atitude científica seja mantida, com regularidade e disciplina: a de registrar todas as informações no diário de campo. As conclusões sobre o território punk de Londrina, por exemplo, foram resultado da somatória de uma série de informações desencontradas e dispersas, mas registradas.

Sempre que passeava com algum punk pela cidade, ouvia relatos de que em tal ou qual lugar, bar, ou prédio abandonado, os punks e as punks se reuniram durante certo período. Sempre que víamos uma foto, relatos remetiam a lugares em que a cena acontecia, a eventos que marcaram sua história e aos locais desses eventos.

Ao registrar todas as informações, mesmo sem saber ao certo por que o fazia, pude, ao final, montar o quebra-cabeça da territorialidade punk em Londrina e reconstruir a sua migração territorial pela cidade, ao longo do tempo, e sua trama territorial no presente.

No processo de registrar as informações, já pode (e deve) estar presente, também, um esforço de interpretação, de modo que a descrição dos fatos, dos diálogos, dos lugares e tempos seja também uma elaboração teórica - no sentido de confronto com a teoria existente - daquilo que está sendo registrado.

Alguns exemplos de trechos do diário de campo, elaborados na pesquisa com as culturas juvenis punk e hip-hop, na cidade de Guarapuava-PR, podem ser reveladores do que estou tentando dizer:

\section{Relato de um show punk:}

Apesar de todo o esforço, percebo ainda certo constrangimento no ar com a minha presença em algumas rodas. São, na maior parte, pessoas muito jovens, com dezesseis/ dezessete anos. O que parece é que para as garotas da Formol [banda musical ativa na cena, durante a pesquisa], o punk é, em grande medida, uma forma de diversão, de curtir som, beber, beijar e, ao mesmo tempo, construir um visual e relações distintivas, 
dentro de um cenário juvenil, marcado pelo predomínio de referências pop da cultura de massa.

Minha presença parecia inibir essa diversão autêntica, pois o punk também tem outro lado mais politizado e racional. Penso que a presença de uma pessoa pesquisando o punk impunha a eles e elas a necessidade de racionalizar discursos e comportamentos, pois estavam sob observação, o que era pesado demais para quem só queria diversão. E o punk tem uma dimensão de diversão que não se pode negar, sem a qual, como diria M., "o negócio fica chato". A própria cultura punk surge como uma forma de articular uma diversão autêntica, criando espaços específicos, fora dos circuitos de diversão juvenil mais tradicionais.

Com este relato, tal como já está implícito, pude tanto reelaborar minha relação com os/as jovens com quem queria dialogar, quanto pensar sobre as várias dimensões da identidade punk e reconhecer que cada uma dessas dimensões pode ser acionada em contextos específicos e também que alguns/as punks, de fato, não poderiam dar respostas em algumas delas, como a dimensão política, ou porque ainda não haviam tomado contato com ela, ou porque simplesmente não desejavam que a cultura punk que assumiram ultrapassasse os limites da mera diversão, do encontro e da festa. Tais considerações apontaram para o fato de que o agrupamento juvenil articulado em torno da cultura punk de Guarapuava poderia ser, internamente, bastante diversificado; um território altamente contestado, como diria Silva (2002), no sentido de uma negociação em torno dos significados dos referentes culturais.

No relato a seguir, essa diversidade se torna mais nítida.

Conversa com o principal informante da cena punk:

[...] ele me relatava alguns eventos interessantes dos quais não pude participar, envolvido que estava em outras atividades acadêmicas. Um que marcou, foi a discussão entre ele e uma das integrantes da banda Formol [...] Ele disse não suportá-la, pois ela se define punk, mas tem umas "ideias muito fracas", que não condizem com a visão informada de mundo que tem os punks. Essa garota, na sua opinião, só quer beber e curtir som, bebe inclusive coca-cola e diz que é o melhor refrigerante do mundo. Numa atitude evidente de provocação em relação aos punks mais ortodoxos.

Disso, é possível pensar, como o mesmo referente punk é vivido e incorporado de formas distintas no lugar. O que é causa de conflitos. O R. é um punk que procura ser fiel a certos princípios do movimento, enquanto essa garota usa este referente, mas não se informa sobre os sentidos mais profundos e políticos da identidade, ficando na superfície da diversão. A diferença de idade entre eles pode também jogar um papel nessas rixas. O R. é mais velho e mais antigo no punk, já faz Faculdade de História, a garota ainda está no Ensino Médio e descobriu o punk recentemente, quando começou a sair de casa para divertir-se sem o ostensivo controle dos pais.

Contudo, ambos pertencem à mesma cena e, ainda que não façam parte da mesma turma, tem muitos amigos em comum. Isso faz pensar que o jogo de proximidades e 
distanciamentos é muito mais complexo do que, normalmente, aparece problematizado na literatura: os mesmos referentes aproximam, mas os usos e sentidos e as formas como cada qual os vivencia provocam novas proximidades e distanciamentos. É preciso considerar, também, que cada um faz suas próprias mesclas entre o referente punk e outros referentes, que marcaram suas histórias de vida, que fazem sentido ainda hoje e dos quais não querem se desvencilhar.

Em síntese: é possível afirmar que, compartilhar os mesmos referentes culturais transterritoriais não significa, necessariamente, construir identidade/amizade entre as pessoas e, certamente, isso joga um papel importante nos modos do acontecer e da territorialização do punk no lugar.

Duas questões podem ser problematizadas a partir deste relato. Primeiro, o fato de o principal informante ser um punk mais engajado e maduro aponta para um perfil comum aos punks com os quais mais tive contato durante o campo. O que contrasta com o relato anterior é que aqueles punks, ainda muito jovens, sentiam-se como que constrangidos diante da minha presença. A isso soma-se o fato de articularem muito mais o referente punk como diversão, do que como posicionamento crítico diante do mundo. Em segundo lugar, o trecho citado, somado a outras evidências que emergiram no campo, aponta para uma conclusão importante quanto às tensões do ajuntamento entre punks com trajetórias de vida diferentes e com horizontes temporais diversos, numa mesma cena.

Autores como Carrano (2001) reconhecem que as referências culturais globais, que chegam aos lugares por meio de mercadorias culturais, ao mesmo tempo em que produzem alienação em relação a referências mais localizadas, oferecem novos vínculos socioafetivos, provendo aproximações diversificadas. Contudo, falta considerar as tensões decorrentes desse novo ajuntamento, uma vez que as culturas juvenis, quando se territorializam no lugar, passam a ter uma trajetória histórica particular, naquele novo contexto. No caso da cultura punk, há punks que aderiram nos primórdios da cena local, há punks que já deixaram de sê-lo, e há aqueles que estão descobrindo o punk agora e fazem suas incursões ao território em que as redes de sociabilidade em torno do punk estão constituídas. Mas nem sempre conseguem conectar-se a essas redes, cujo acesso é controlado pelos punks mais velhos, que, dessa forma, exercem um poder sobre a cultura punk local e um controle do acesso aos seus territórios.

Os mesmos embates e dilemas podem ser encontrados também na cultura hip-hop, conforme o trecho do diário de campo a seguir.

\section{Diálogo com um importante informante do hip-hop:}

Dia vinte e um de dezembro, em visita aos garotos do [grupo de rap] Proceder Periférico, conversei longamente com o L. sobre a OUAR ${ }^{3}$. Ele disse que está "meio esquisita" e que ele queria que fosse diferente, que todos pudessem participar, dar opiniões.

3 OUAR - Organização Uniação, Atitude e Reação. Uma ONG organizada por membros de longa data do movimento hip-hop de Guarapuava, com vistas a dar direcionamento e visibilidade às ações do movimento, promover shows de grupos locais e eventos em que todos os elementos da cultura pudessem se manifestar. 
Ele falou que chegam os mais velhos e ficam dando ordens, sem fazer discussão. Eles chegam com as coisas já prontas e decididas e caberia ao pessoal acatar, o que tem contribuído também para que os projetos não funcionem. Ele deixou de ir às reuniões, há algum tempo, justamente por isso.

Essa é uma ideia geral entre os grupos de rap estudados, de que a OUAR precisa ser mais democrática e talvez esse seja mesmo seu grande desafio: jovens que nunca experimentaram relações democráticas em outros contextos, tendo que construir relações democráticas entre si, na organização de um movimento que se propõe social. Os novatos querem construir juntos a OUAR e não chegar, nas reuniões, e encontrar as mesmas relações hierárquicas que abominam na escola e na família. Era o que reivindicavam durante nossas conversas em campo.

A partir dessas anotações, pude concluir que a vivência numa cultura juvenil nem sempre conduz as pessoas a uma aproximação inconteste, mas conduz a novas clivagens entre quem assume o referente cultural como parte de sua vida e quem apenas quer se divertir e encontra no punk ou no hip-hop um contexto propício para isso e entre quem tem uma vivência mais intensa e prolongada e aqueles/as que estão apenas começando. No caso do hip-hop, os mais velhos já são ligados a outros compromissos sociais e políticos, enquanto os novatos têm no movimento, importante espaço, se não o principal, de viver uma juventude possível, num contexto de diversas carências.

Assim, o contato com os universos punk e hip-hop, pela observação participante, permitiu-me concluir que estava diante de grupos que não tinham nada de homogêneo, apesar de as pessoas dizerem compartilhar o mesmo referente cultural. Permitiu-me observar que a vivência da cultura juvenil é variável conforme a origem socioespacial do sujeito, sua idade e as relações que estabelece no meio. Uma diversidade que é objeto de conflitos internos, que contribuem, por sua vez, para a fragilização do que poderia representar a emergência de um sujeito político no lugar, pela constituição de um movimento social juvenil.

Claro que essas conclusões, elaboradas a partir da observação participante, foram reforçadas pelo emprego de outras metodologias de produção de informações. Entrevistas, individuais ou em grupo podem oferecer depoimentos sistematizados na forma de documentos orais - as entrevistas transcritas -, pelos quais as impressões do observador/a em campo são testadas - ainda mais se a observação participante oferecer o repertório para a elaboração do roteiro de entrevista. Nesse sentido, Winkin (1998), por exemplo, recomenda que não se realizem entrevistas antes de dispor de uma trajetória mínima de observação, pois antes de conseguir chaves interpretativas do universo estudado, a partir de seus próprios sujeitos, é importante que o pesquisador/a tenha suas próprias interpretações, pelas quais pode dialogar com os sujeitos, numa situação formal de entrevista.

Pais (2003), na sua pesquisa sobre culturas juvenis em Lisboa, também realiza essa mescla de metodologias qualitativas e argumenta que entre o que escutou nas entrevistas e o que escutou em conversar informais, enquanto estava no campo com os jovens, há uma grande diferença, a ponto de parecer que as falas, em cada contexto metodológico, 
foram produzidas por sujeitos bastante distintos. O que não é necessariamente um problema, mas um fato sobre o qual se deve pensar, afinal, duas metodologias fizeram emergir informações diferentes, cujo confronto pode ser revelador das ambiguidades e contradições presentes no grupo estudado.

Na elaboração do roteiro de entrevista, segui a recomendação de Becker (1999) de perguntar sempre "como?" e nunca "por quê?". Segundo o autor, perguntar por que as pessoas fazem o que fazem é pedir uma justificativa, uma análise dos fatos, o que deveria ser função do/a pesquisador/a, além de cair numa ideologização dos discursos, na qual as pessoas argumentam no sentido de ligar seus atos aos discursos preestabelecidos do grupo (uma resposta ideológica e não pessoal). Ao contrário, perguntar como algo aconteceu significa permitir que o discurso entre numa sequência narrativa, na qual se conta a história de um processo, e as ideologias ficam mais esquecidas. Nesse caso, não se pede uma explicação ou justificativa, mas sim os passos que conduziram a determinado acontecimento.

Por fim, o processo de saída do grupo é outra questão delicada que merece atenção e que não creio que chegue a ocorrer completamente. O que ocorre de fato é a necessidade de recuperar a identidade de pesquisador/a e colocar um ponto final na interação, do contrário, novas informações serão produzidas em cada novo contato. Também considero fundamental um período de isolamento total do mundo para a elaboração da experiência de pesquisa, em termos mais racionais, um momento em que o diário de campo se torna o principal companheiro do pesquisador/a. É o período da sistematização das informações e da redação final da pesquisa, discussão que passo a desenvolver no próximo ponto.

\section{SISTEMATIZANDO AS INFORMAÇÕES}

Finalizada a pesquisa empírica e diante da incumbência de elaborar a sua redação, o desafio que se coloca é: como organizar o material empírico, um conjunto de informações ricas, com alto grau de detalhamento, mas pouco mensurável?

Nas minhas pesquisas, diante dessa questão, tenho seguido as recomendações de Becker (1999) sobre a descrição da "história natural de nossas conclusões" , que consiste em apresentar

[...] as evidências tal como chegaram à atenção do observador durante os sucessivos estágios de conceitualização do problema. O termo 'história natural' não implica a apresentação de cada um dos dados, mas somente das formas características que os dados assumiram em cada estágio da pesquisa. [...] Desse modo, a evidência é avaliada à medida que a análise substantiva é apresentada. Se este método for empregado, o leitor será capaz de acompanhar os detalhes e ver como e em que bases se chegou a qualquer das conclusões. Isso daria ao leitor [...] a oportunidade de fazer seu próprio julgamento quanto à adequação da prova e ao grau de confiança a ser atribuído à conclusão (p. 64). 
Na produção final do texto, momento de interpretação e de construção teórica, também os comentários de Geertz (1978) têm implicações importantes, pois indicam qual dimensão assume a teoria no processo. Para o autor, "se a interpretação antropológica está construindo uma leitura do que acontece, então, divorciá-la do que acontece [...] é divorciá-la das suas implicações e torná-la vazia" (p. 28). Ou seja, a interpretação não pode pretender alçar voos teóricos demasiadamente generalizantes, mas antes mergulhar no caso estudado.

Ainda para este autor, a descrição etnográfica é, sobretudo, interpretativa e microscópica. O que não significa que a Antropologia não trabalhe em grande escala. Mas o antropólogo aborda as interpretações mais amplas a partir de um conhecimento extensivo de assuntos muito pequenos.

Diante da descrição densa, certamente, a teoria não dá a última palavra. Não é para confirmar teorias pré-formuladas que a pesquisa com observação participante é feita. $\mathrm{O}$ que não significa que elas não tenham um importante papel. Não se vai ao campo destituído de uma imagem dos sujeitos de pesquisa, nem sem um conhecimento prévio dos seus contextos de vida e de análises macrossociais sobre o mundo contemporâneo. Mas no campo, como já foi revelado, o que vale é escutar atentamente o que aquela realidade particular tem a dizer sobre si mesma e, na maior parte dos casos, o que é dito escapa à teoria.

Nesse sentido, o esforço de realizar uma descrição densa deve ser orientado para produzir uma teorização própria ao caso estudado. Uma nova teoria que pode tensionar aquela já elaborada, ou ao menos dar ritmo, cor, som e movimento para os conceitos, com os quais a pesquisadora e o pesquisador procuram cercar teoricamente a realidade. Conceitos que são, no fundo, um repertório por meio do qual a interpretação pode ser tecida (GEERTZ, 1978).

Em todo caso, nas pesquisas com observação participante, as teorias devem sobreviver aos casos concretos - uma forma de atestar sua validade. Trata-se de um confronto, na verdade, entre a teoria acumulada e a realidade que coloca novos problemas à compreensão (LACERDA, 2003). E é esse confronto que faz da descrição densa muito mais que uma descrição gratuita e que permite que o trabalho possa ser avaliado criticamente por outras pesquisadoras e pesquisadores. Nesse sentido, não se furta ao debate acadêmico.

\section{ALGUMAS QUESTÕES PARA O DEBATE}

Para finalizar, mais do que fazer a síntese do que foi apresentado ao longo do texto, prefiro abrir uma nova frente de questões sobre as quais tenho procurado estabelecer interlocução em oportunidades como esta. Trata-se de pensar sobre a especificidade da Geografia no debate em torno da íntima relação do espaço (no caso urbano) como meio e condição das tessituras de relações sociais, produtoras de (micro)territórios na cidade. 
O diálogo interdisciplinar é fundamental, pela leitura do que se produz em outras ciências. Mas isso não pode nos servir de pretexto para abandonarmos a Geografia e fazermos qualquer outra coisa.

A Geografia pensa em termos de próximo e distante, de deslocamento e repouso, de área e trajeto, de território, lugar, espaço, de relações de escala etc., ou seja, a Geografia pensa em termos espaciais. Essa é sua especificidade analítica, é a base de seu discurso.

Mas não pode ficar só nisso, pois aí, a única diferença que existiria entre a Geografia e a Sociologia, por exemplo, seria que a Geografia espacializa as relações sociais, as mapeia, sendo que a explicação/compreensão do que acontece estaria na leitura dos sociólogos. De modo que a produção dos geógrafos seria um conhecimento, uma informação que não faz muita diferença no desvendamento dos processos sociais.

É preciso avançar e pensar que o espaço em que as relações sociais se espacializam não é neutro. O espaço é, ele mesmo, uma construção histórica e social e, por isso, a produção do espaço nos interessa e poderia (ou deveria?) ser o ponto de partida da análise, com toda a complexidade que ela envolve.

A partir daí, poderíamos pensar sobre o papel que o espaço produzido desempenha na espacialização das relações sociais. A relação estreita entre ambos (espaço produzido e espacialização das relações sociais, constituindo territórios) coloca-nos no campo da dialética socioespacial, o que não é novo na Geografia, mas, historicamente, a preocupação tem se voltado mais para as formas como o espaço "reflete" a sociedade, do que para as formas como o espaço condiciona a sociedade que o produziu.

Penso que devemos empreender esforços teóricos e metodológicos para desvendar esse segundo movimento da dialética socioespacial. Mas como demonstrar empiricamente as influências do espaço produzido na vida social?

Eis uma questão que penso valer a pena perseguir, pois uma das conclusões comuns às pesquisas de Londrina e de Guarapuava foi que, em cidades de porte médio, longe dos contextos metropolitanos, as culturas punk e hip-hop realizam-se de forma bastante particular, tendo que se haver com os recursos de urbanidade que ali encontram disponíveis, de modo que a escala da cidade joga um papel importante nas formas de acontecer dessas culturas.

Portanto, territorialização e particularização são processos que acontecem paralelamente, o que aponta muito mais para diversidades, pluralidades, do que para homogeneização cultural. Afinal, é preciso reconhecer o poder que o espaço tem, enquanto lugar, de relativizar fenômenos e processos globais.

\section{REFERÊNCIAS}

BECKER, H. S. Métodos de pesquisa em ciências sociais. São Paulo: HUCITEC, 1999.

CARRANO, P. C. R. Jovens na cidade. Trabalho e sociedade. Rio de Janeiro, ano 1, n. 1, p. 15 - 22, agosto de 2001.

CICOUREL, A. Teoria e método em pesquisa de campo. In: GUIMARÃES, A. Z. (Org.). Desvendando máscaras sociais. Rio de Janeiro: Livraria Francisco Alves Editora, 1980. p. 87-121. 
CLAVAL, P. A geografia cultural: o estado da arte. In: CORREAA, R. L.; ROSENDAHL, Z. Manifestações da cultura no espaço. Rio de Janeiro: EdUERJ, 1999.

As abordagens da geografia cultural. In: CASTRO, I. E. de; GOMES, P. C. da C.; CORRÊA, R. L. (Org.). Explorações geográficas: percursos no fim do século. Rio de Janeiro: Bertrand Brasil, 1997.

DA MATTA, R. O ofício do etnógrafo, ou como ter anthropological blus. In: NUNES, E. de O. (Org.). A aventura sociológica: objetividade, paixão, improviso e método na pesquisa social. Rio de Janeiro: Zahar, 1978. p. 23 - 35.

DAYRELL, Juarez. A música entra em cena: o rap e o funk na socialização da juventude. Belo Horizonte: Humanitas, 2005.

DIÓGENES, G. Cartografias da cultura e da violência: gangues, galeras e movimento hip hop. São Paulo: Annablume; Fortaleza: Secretaria da Cultura e do Desporto, 1998.

GEERTZ, C. A interpretação das culturas. Rio de Janeiro: Zahar, 1978.

HAESBAERT, R. O mito da desterritorialização: do "fim dos territórios" à multiterritorialidade. Rio de Janeiro: Bertrand Brasil, 2004.

LACERDA, E. P. Trabalho de campo e relativismo: a alteridade como crítica da antropologia. Disponível em: <www.antropologia.com> Acesso em: 23 jul. 2003.

PAIS, J. M. Culturas juvenis. Lisboa: Imprensa Nacional; Casa da Moeda, 2003.

SILVA, T. T. da. Documentos de identidade: uma introdução às teorias do currículo. Belo Horizonte: Autêntica, 2002.

TURRA NETO, N. Enterrado vivo!: identidade punk e território em Londrina - Pr. São Paulo: EDUNESP, 2004.

Múltiplas trajetórias juvenis em Guarapuava: territórios e redes de sociabilidade. 2008. 516 f. Tese (Doutorado em Geografia) - Pós-Graduação em Geografia, Universidade Estadual Paulista. Presidente Prudente: 2008.

WINKIN, Y. Descer ao campo. In: A nova comunicação: da teoria ao trabalho de campo. Campinas: Papirus, 1998. p. 129-145.

Recebido em 14/01/2012

Aceito para publicação em 22/03/2012 